\title{
Article \\ Podiatric and Stabilographic Examinations of the Effects of School Bag Carrying in Children Aged 11 to 15 Years
}

\author{
Joanna M. Bukowska ${ }^{1}{ }^{\oplus}$, Małgorzata Jekiełek ${ }^{2}{ }^{\circledR}$, Dariusz Kruczkowski ${ }^{3}{ }^{\circledR}$, Tadeusz Ambroży ${ }^{4}(\mathbb{D}$, \\ Łukasz Rydzik ${ }^{4, *}$, Michał Spieszny ${ }^{4}$, and Jarosław Jaszczur-Nowicki ${ }^{1, *}$ \\ 1 Department of Tourism, Recreation and Ecology, University of Warmia and Mazury, \\ 10-719 Olsztyn, Poland; joanna.bukowska@uwm.edu.pl \\ 2 Department of Ergonomics and Physiological Effort, Institute of Physiotherapy, Jagiellonian University \\ Collegium Medicum, 31-126 Krakow, Poland; malgorzata.jekielek@gmail.com \\ 3 Faculty of Health Sciences, Elblag University of the Humanities and Economics, 82-300 Elblag, Poland; \\ dyrektor@olimpijczyk.gda.pl \\ 4 Institute of Sports Sciences, University of Physical Education, 31-571 Krakow, Poland; \\ tadek@ambrozy.pl (T.A.); michal.spieszny@awf.krakow.pl (M.S.) \\ * Correspondence: lukasz.gne@op.pl (Ł.R.); j.jaszczur-nowicki@uwm.edu.pl (J.J.-N.); \\ Tel.: +48-730-696-377 (Ł.R.)
}

check for updates

Citation: Bukowska, J.M.; Jekiełek, M.; Kruczkowski, D.; Ambroży, T.; Rydzik, Ł.; Spieszny, M.;

Jaszczur-Nowicki, J. Podiatric and Stabilographic Examinations of the Effects of School Bag Carrying in Children Aged 11 to 15 Years. Appl. Sci. 2021, 11, 9357. https://doi.org/ 10.3390/app11199357

Academic Editor: Philip Fink

Received: 30 August 2021

Accepted: 4 October 2021

Published: 8 October 2021

Publisher's Note: MDPI stays neutral with regard to jurisdictional claims in published maps and institutional affiliations.

Copyright: (c) 2021 by the authors. Licensee MDPI, Basel, Switzerland. This article is an open access article distributed under the terms and conditions of the Creative Commons Attribution (CC BY) license (https:/ / creativecommons.org/licenses/by/ $4.0 /)$.

\begin{abstract}
Background: The issues raised in this study were inspired by the concern for the musculoskeletal status of school children. Carrying excess weight in the form of a school bag in this period of life affects the correct body posture of school children. The aim of the study was to analyze the influence of school bags on the feet force distribution on the ground and postural balance in children of both sexes between 11 and 15 years of age. Methods: The study investigated the distribution of pressure forces on the sole of the foot and its arch. The center of pressure for both feet and the whole body was also examined. The participants were 100 students from primary schools in Gdańsk, aged 11 to 15 , including 54 girls and 46 boys. The research used a podobarographic platform that measures the distribution of foot pressure to the ground. The examinations included two measurements: in the first, the children stood on the platform in a natural position. Then, a $5 \mathrm{~kg}$ backpack was put on and they stood on the platform again. Results: Statistically significant differences were found in the distribution of the foot pressure on the ground in the left metatarsus $(p=0.000)$ and heel $(p=0.000)$ after putting on the backpack in both girls and boys. However, in the right foot, these differences concerned the metatarsal area $(p=0.001)$. The results of the balance tests were only statistically significant in the group of girls in the right foot sway area $(p=0.020)$. Conclusions: The school backpack load led to an increase in the values of the heel and metatarsal area measured in the students, causing its flattening.
\end{abstract}

Keywords: adolescent; teenagers; backpack; stability; overload; school

\section{Introduction}

School children are teenagers who experience a period of rapid growth and development of bone and soft tissues. Spinal structures in children are more susceptible to disturbances caused by external factors compared to those in adults. Furthermore, external forces caused by load transmission may also influence growth, development, and correct posture [1]. Increased body weight in children is associated with increased pressure on the plantar side of the developing foot. Child obesity can weaken the structure and function of the foot, exposing children to pain and discomfort in the feet [2,3]. An external load in the form of a school backpack, often used by children during the school period, may also have a negative impact on joints, bone health, and body posture [4]. According to reports in the literature, the prevention of backpack-related musculoskeletal problems in primary school students is a serious problem [5]. Research by $\mathrm{Hu} \mathrm{H}$ et al., carried out on four age 
groups, showed that despite different loads, there are statistically significant differences in the body posture in each group between the tests with and without loads [6]. There is ample evidence that wearing a backpack affects students' health. Research shows that the relationship between the student's body weight and the weight of his or her backpack is very often incorrect. It is not rare that the child's backpack is heavier than $10 \%$ of their body weight, which is the value recommended in the literature [5,7-9]. As the load to the body increases, especially after exceeding the recommended backpack weight, significant kinematic changes in the ankle, knee, and hip joints are observed, both in children and adults. They affect both gait and pressure on the plantar side of the foot $[10,11]$. The human foot is an important part of the musculoskeletal system that transfers both static and dynamic load. Its shape is different in every human being. Its structure and positioning have a great effect on gait quality and postural stability. A properly arched foot is flexible and prevents micro-injuries and shocks during locomotion. The correct shape of the foot depends on the efficiency of the muscles and ligaments and the structure of the osteoarticular system [12]. Wearing too heavy a backpack may cause increased strain on joints and problems with maintaining dynamic stability and balance [13]. Body balance is defined as the ability of the human body to maintain its position. Body balance is genetically determined and, at some stage of development, the ability to maintain balance is hampered by the fact that the brain already has a fully formed set of neurological connections. Similarly, motor skills are already shaped [14], for example, by developed movement patterns and habits developed in everyday life. The aim of this study was to analyze the influence of the backpack on the distribution of foot forces on the ground and body balance in children (boys and girls) aged 11 to 15 years.

\section{Materials and Methods}

\subsection{Participants}

The criterion of purposeful selection was used in the study. The inclusion criterion was the consent of parents or legal guardians to participate in the study. Only $15 \%$ of the recruited participants refused to participate in the study. At the beginning of the recruitment, participants were verbally informed about the purpose and nature of the study and its benefits. The only coherent factor for the selection was the implementation of the educational and prevention program, with one of the goals being to develop healthy attitudes of students in the field of proper motor development and body posture. The research was conducted on children with increased physical activity. The study included 100 children aged 11 to 15 , including 54 girls and 46 boys. In the group of girls, the mean body height was $149 \mathrm{~cm}(\mathrm{SD}=9 \mathrm{~cm})$, with an average body weight of $41 \mathrm{~kg}(\mathrm{SD}=8.4 \mathrm{~kg})$. In boys, these somatic parameters were $152.6 \mathrm{~cm}(\mathrm{SD}=11.3 \mathrm{~cm})$ and $45.7 \mathrm{~kg}(\mathrm{SD}=13.2 \mathrm{~kg})$, respectively. All respondents were students of Gdańsk primary schools and reported a good health status and no injuries. The headmasters and parents/legal guardians agreed to the participation of the children in the research. Both the guardians and the children were familiarized with the research procedure that was carried out in accordance with the International Charter of Ethical Research in Children. The research was also conducted based on the approval of the Scientific Research Ethics Committee of the University of Warmia and Mazury in Olsztyn (Decision No. 9/2018).

\subsection{Instruments}

The participant's body height was measured with a Soehnle electronic ultrasonic height measuring device (Soehnle, Gaildorfer Straße 6, 71522 Backnang, Germany), which features an ultrasound system, and the built-in tilt sensor allows for precise measurement. The E.P.S./R1 mat with 2304 pressure sensors located on the active surface (Letsens Group, Letsens S.R.L. Via Buozzi, CastelMaggiore, Bologna, Italy) was used to measure the percentage distribution of foot forces on the ground and body balance. The mat size is $700 \mathrm{~mm} \times 500 \mathrm{~mm} \times 5 \mathrm{~mm}$. Sensors placed in the mat collect the measurements for $20 \mathrm{~s}$ and automatically transfer them to a computer using the Biomech Studio program 
(Biomech Studio 2.0 Manual, Letsens Group, Letsens SRL Via Buozzi, CastelMaggiore, Bologna, Italy). The following parameters can be tested using the mat:

Load on the right and left feet (\%);

Pressure on the forefoot, metatarsal area, and heel (expressed in \%); COP-bars-the area of the body's center of gravity $\left(\mathrm{mm}^{2}\right)$;

1-bars-left foot imbalance area, $\left(\mathrm{mm}^{2}\right)$;

r-bars-right foot imbalance area, $\left(\mathrm{mm}^{2}\right)$.

\subsection{Procedure}

The examination was preceded by a diagnosis. The tests were conducted at rest, without load, and with the load of a $5 \mathrm{~kg}$ backpack. This weight was the mean weight of 20 randomly selected backpacks. Random sampling was used to select children for the study. Children participating in the study were students from Gdańsk schools aged from 11 to 15 years old with normal weight and normal weight indices $(n=100)$. The test procedure consisted of several steps. In the initial stages, consultations with headmasters and parents were conducted regarding the planned study. The study schedule was also drawn up and parental consent was obtained for the examination. All parents gave their written consent for their children to participate in the study. A specially developed parental informed consent form was used for this purpose. The experimental sessions were held in gyms to correct postural defects. Natural light was used in the room and the participants were offered privacy to avoid external influences. Each participant was examined in a single session so all the tasks could be performed in the same conditions (ambient temperature: $22{ }^{\circ} \mathrm{C}$ ). The research was conducted in May 2019. In order to collect data for gait analysis, each subject was anonymously registered in the Biomech software (Biomech Studio 2.0 Manual) along with the following data: participant's code, date of birth, sex, and body weight and height measured by the researcher using a height-measuring device while maintaining an upright posture. The platform was placed on the floor and connected with a USB cable to a computer that saved the data from the analysis to the Biomech program.

\subsection{Measurement Protocol}

After undressing to underwear, the examined child went to the podographic mat so that his or her feet were on both sides of the vertical line drawn on the mat. In preparation for the study, participants were asked to take a few steps to place their feet freely on the mat. The child stood barefoot, upright, with his or her arms against the body, in a natural position looking straight ahead at a fixed point at eye level. The participant remained stationary for $20 \mathrm{~s}$. At that time, the measurements were made and transferred to a computer system using the Biomech Studio software. Then, the child put on a $5 \mathrm{~kg}$ backpack, the backpack adjustment straps were loosened, and the participants were asked to adjust them as they usually do with their backpacks. Then, the procedure was repeated on the stabilographic mat. The study design is shown in Figure 1.

The Biomech Studio program allows data regarding the foot type, longitudinal arch, percentage distribution of forces on the sole of the foot (Figure 2) to be read, as well as data from the stabilometric evaluation, such as the area of the body's center of gravity, left foot imbalance area, and right foot imbalance area (Figure 3). 


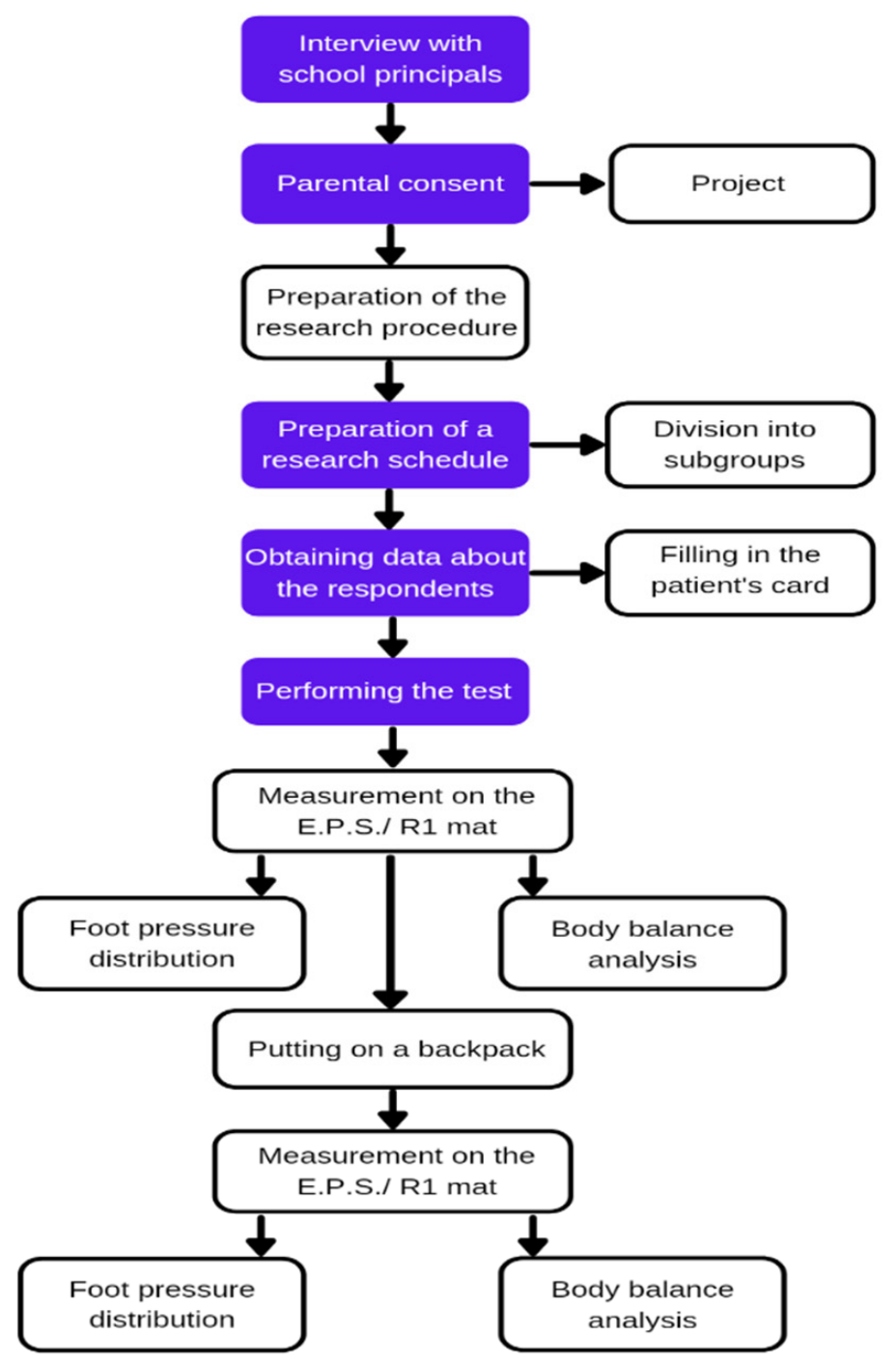

Figure 1. Scheme of the test procedure.

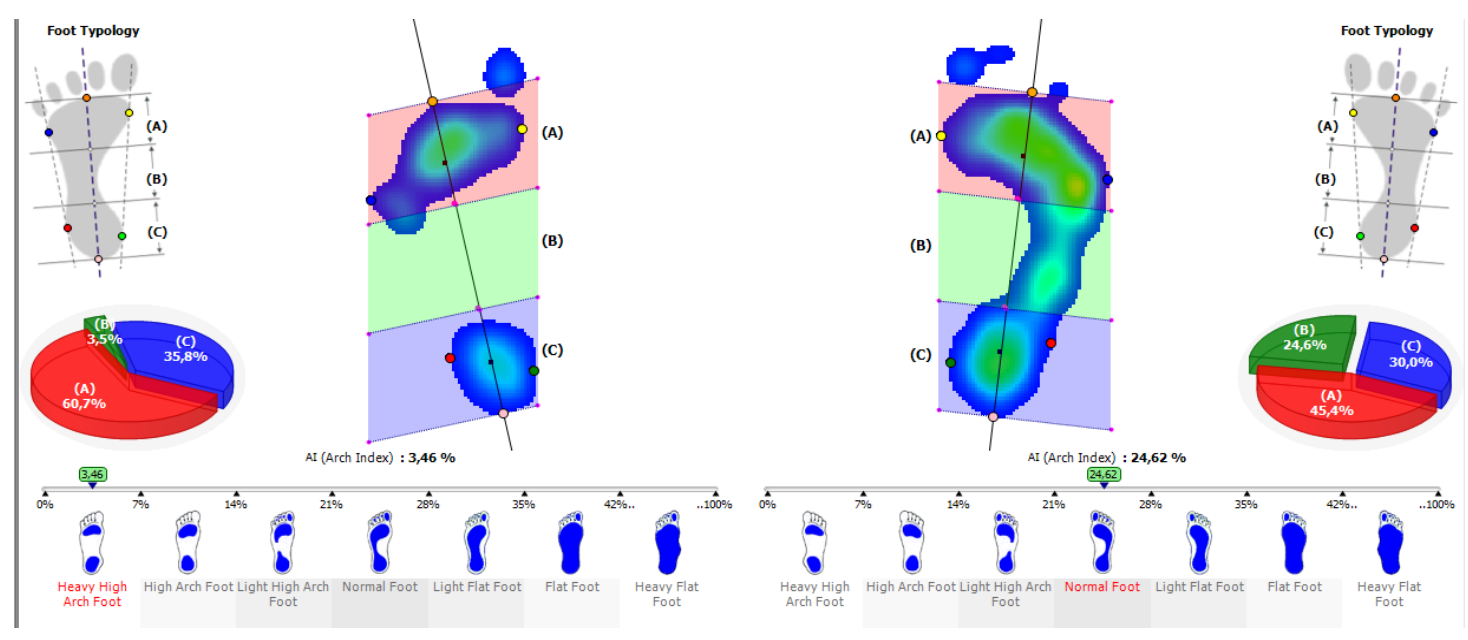

Figure 2. An example image with the results of pressure distribution on the sole of the foot from the Biomech Studio software. 


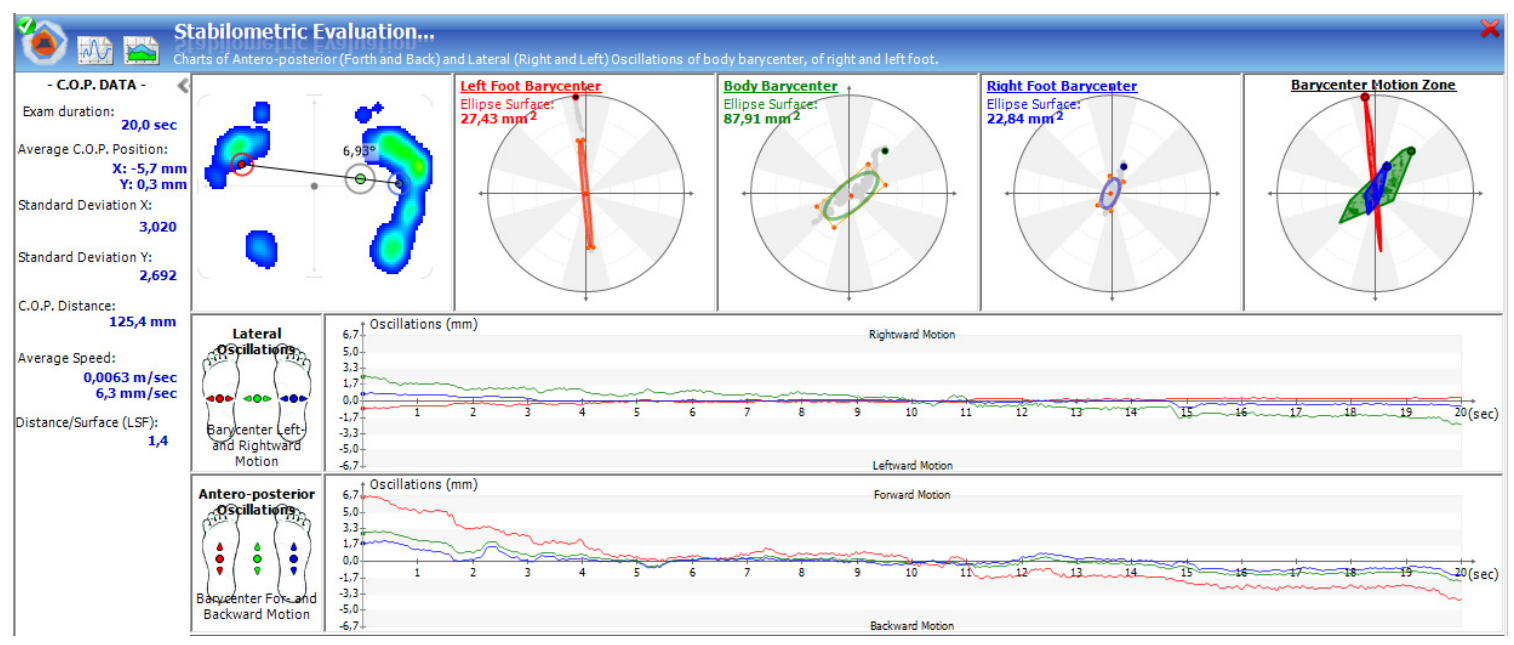

Figure 3. Sample image with the balance results from the Biomech Studio program.

\subsection{Data Analysis}

The size of the longitudinal arch of the foot in the population of children in early adolescence and adolescence should have a normal distribution. However, in the foot load study design, it can be assumed that data distribution does not follow the normal distribution; therefore, it was decided to verify the appropriate statistical treatment in relation to the sample size. The Shapiro-Wilk test used for the analysis showed inconsistency with the normal distribution for all measurement parameters. Therefore, in further analysis, a statistical non-parametric method (the Wilcoxon pairwise test) was employed. Additionally, the Cohen effect size was calculated. For the characteristics of descriptive statistics, the measure of the median was used: the median and the dispersion of the measurement values (quartiles). The significance level in the study was set at $p<0.05$. Statistical analyzes were performed using the Statistica program (StatSoft Polska, Kraków, Poland, version 13.3).

\section{Results}

Measurements of the studied population of girls and boys at rest for both feet recorded the median corresponding to a significant hollow of the longitudinal arch of the foot. The margin of a significant cavity for the metatarsal area is 0 to $7 \%$. The median of the total population in the authors' research was $6.6 \%$ for the left foot and $6.8 \%$ for the right foot (Table 1). After loading with a $5 \mathrm{~kg}$ backpack, the median increased and changed the range for both feet corresponding to the mean hollow of the foot arch (from 7 to $14 \%$ of the metatarsal cavity). The median was $10.1 \%$ for the left foot and $9.9 \%$ for the right foot. Comparison of the mean measurement results between the populations of girls and boys revealed differences in the size of the longitudinal arch of the foot both in the examinations at rest and after loading with a $5 \mathrm{~kg}$ backpack (Table 1). In both tests, the mean result in the population of girls indicated a hollow foot, with the medians of $\mathrm{S}=6 \%$ and $\mathrm{O}=8.8 \%$ for the left foot and $\mathrm{S}=5.2 \%$ and $\mathrm{O}=9.6 \%$ for the right foot. In the case of the male population, the mean result characterized an average hollow foot, with $\mathrm{S}=11.2 \%$ and $\mathrm{O}=13.2 \%$ for the left foot, and $\mathrm{S}=12.4 \%$ and $\mathrm{O}=13.4 \%$ for the right foot. Under load conditions, in both studied populations, the medians for both feet were recorded, reducing their longitudinal arch. In the population of girls, the values increased by $2.8 \mathrm{pp}$ in the left foot and $4.4 \mathrm{pp}$ in the right foot. Furthermore, in the population of boys, the medians increased by 2 and $1 \mathrm{pp}$, respectively. In both populations, the values were classified as an average hollow. Analysis of the statistical significance of the differences in the magnitude of the longitudinal arch of the feet in the studied population of girls and boys aged 11-15 years revealed significant differences in the longitudinal arch for the left and right feet (Table 1). Similar differences, significant for both feet, were found in the populations of girls and boys for the left foot. 
There was also a homogeneous trend of changes for the populations studied in the load on the heel area of both feet (Table 1). These differences were not statistically significant in the right foot, with a mean reduction in the load by $0.8 \%$ for the entire study population $(0.6 \%$ for girls and $1.7 \%$ for boys). In the case of the left foot, they were statistically significant, with the load being decreased by $2.7 \%$ (3.4\%, and $1.6 \%$, respectively). In all analyzed parameters of the studied populations, the Cohen effect size was small (Table 1).

Table 1. Distribution of the results of the tests for the pressure of the foot on the ground at rest and after loading with a backpack in the study group; the Wilcoxon Matched Pairs Test.

\begin{tabular}{|c|c|c|c|c|c|c|c|c|c|c|c|c|}
\hline \multirow[t]{2}{*}{ Foot Area (\%) } & \multicolumn{2}{|c|}{ L Forefoot } & \multicolumn{2}{|c|}{ L Metatarsus } & \multicolumn{2}{|c|}{ L Heel } & \multicolumn{2}{|c|}{ R Forefoot } & \multicolumn{2}{|c|}{ R Metatarsus } & \multicolumn{2}{|c|}{ R Heel } \\
\hline & $S$ & $\mathbf{O}$ & $S$ & $\mathbf{O}$ & $S$ & $\mathbf{O}$ & $\mathrm{S}$ & $\mathbf{O}$ & $S$ & $\mathbf{O}$ & $S$ & $\mathbf{O}$ \\
\hline \multicolumn{13}{|c|}{ boys and girls $(n=100)$} \\
\hline$\underline{x}$ & 47.85 & 47.72 & 10.31 & 12.72 & 41.84 & 39.77 & 53.39 & 53.21 & 10.92 & 12.29 & 35.69 & 34.50 \\
\hline SD & 8.96 & 8.72 & 9.86 & 10.23 & 9.11 & 8.12 & 9.33 & 9.67 & 10.42 & 10.55 & 8.14 & 8.46 \\
\hline $\mathrm{Me}$ & 47.5 & 46.8 & 6.6 & 10.1 & 41.0 & 38.3 & 52.0 & 54.2 & 6.8 & 9.9 & 35.5 & 34.7 \\
\hline $\mathrm{Q}_{1}$ & 43.3 & 43.4 & 1.3 & 3.4 & 34.8 & 34.0 & 47.7 & 47.1 & 1.2 & 2.1 & 30.9 & 29.0 \\
\hline $\mathrm{Q}_{3}$ & 54.2 & 53.4 & 19.9 & 22.2 & 46.5 & 45.2 & 61.4 & 58.6 & 20.1 & 21.7 & 40.6 & 40.0 \\
\hline $\mathrm{p}$ & \multicolumn{2}{|c|}{0.836} & \multicolumn{2}{|c|}{$0.000 *$} & \multicolumn{2}{|c|}{0.000 * } & \multicolumn{2}{|c|}{0.549} & \multicolumn{2}{|c|}{$0.001 *$} & \multicolumn{2}{|c|}{0.115} \\
\hline $\mathrm{d}$ & \multicolumn{2}{|c|}{0.01} & \multicolumn{2}{|c|}{0.24} & \multicolumn{2}{|c|}{0.32} & \multicolumn{2}{|c|}{0.02} & \multicolumn{2}{|c|}{0.14} & \multicolumn{2}{|c|}{0.13} \\
\hline \multicolumn{13}{|c|}{ girls $(n=54)$} \\
\hline$\underline{x}$ & 47.17 & 47.16 & 9.54 & 12.35 & 43.28 & 40.88 & 53.66 & 52.80 & 9.69 & 11.33 & 36.65 & 35.87 \\
\hline SD & 9.75 & 9.50 & 9.48 & 10.42 & 9.53 & 8.20 & 9.69 & 8.93 & 9.91 & 9.79 & 8.47 & 7.60 \\
\hline $\mathrm{Me}$ & 47.3 & 47.0 & 6.0 & 8.8 & 42.5 & 39.1 & 52.4 & 54.4 & 5.2 & 9.6 & 36.4 & 35.8 \\
\hline $\mathrm{Q}_{1}$ & 42.9 & 42.6 & 2.0 & 3.0 & 36.3 & 35.4 & 48.7 & 47.0 & 1.1 & 2.1 & 32.1 & 31.3 \\
\hline $\mathrm{Q}_{3}$ & 54.3 & 52.5 & 18.2 & 22.3 & 46.5 & 46.7 & 62.2 & 58.2 & 19.0 & 20.5 & 41.8 & 41.8 \\
\hline $\mathrm{p}$ & \multicolumn{2}{|c|}{0.757} & \multicolumn{2}{|c|}{$0.001 *$} & \multicolumn{2}{|c|}{0.013 * } & \multicolumn{2}{|c|}{0.270} & \multicolumn{2}{|c|}{0.004 * } & \multicolumn{2}{|c|}{0.408} \\
\hline $\mathrm{d}$ & \multicolumn{2}{|c|}{0.00} & \multicolumn{2}{|c|}{0.30} & \multicolumn{2}{|c|}{0.24} & & & & & & \\
\hline & & & & & boys & $=46)$ & & & & & & \\
\hline$\underline{x}$ & 48.64 & 48.38 & 11.22 & 13.16 & 40.14 & 38.45 & 53.08 & 53.70 & 12.35 & 13.42 & 34.56 & 32.88 \\
\hline SD & 7.95 & 7.77 & 10.31 & 10.09 & 8.39 & 7.91 & 8.99 & 10.56 & 10.92 & 11.39 & 7.67 & 9.19 \\
\hline $\mathrm{Me}$ & 48.6 & 48.4 & 11.2 & 13.2 & 40.1 & 38.5 & 53.1 & 53.7 & 12.4 & 13.4 & 34.6 & 32.9 \\
\hline $\mathrm{Q}_{1}$ & 8.0 & 7.8 & 10.3 & 10.1 & 8.4 & 7.9 & 9.0 & 10.6 & 10.9 & 11.4 & 7.7 & 9.2 \\
\hline $\mathrm{Q}_{3}$ & 27.3 & 27.3 & 0.0 & 0.0 & 27.1 & 25.9 & 28.4 & 26.5 & 0.0 & 0.0 & 19.3 & 10.6 \\
\hline $\mathrm{p}$ & & & & & & & & & & & & \\
\hline $\mathrm{d}$ & & & & & & & & & & & & \\
\hline
\end{tabular}

L-left foot, R-right foot, $\underline{X}$-average, SD—standard deviation, Me-median, $\mathrm{Q}_{1}, \mathrm{Q}_{3}$-quartiles 1 and $3, \mathrm{~S}$-resting measurement,

$\mathrm{O}-$ measurement with a backpack, $\mathrm{p}$-significance level of Wilcoxon Matched Pairs Test, ${ }^{*}$ —statistical significance, $\mathrm{d}$ - effect size.

The analysis of the posturographic examination showed differences between the measurement at rest and the measurement with a backpack in the examined girls and boys (Table 2). The mean measurement values for the population of girls and boys are different. Taking into account the parameter of total changes in the area of the center of gravity, an increase of approximately $35 \mathrm{~mm}^{2}$ in the population of girls and a decrease in the median by nearly $30 \mathrm{~mm}^{2}$ in the population of boys was observed. Statistically significant differences in the body balance at rest and after loading with a backpack were shown only for the population of the examined girls in the case of the left leg, with an increase in balance disturbance observed as slightly more than $4.84 \mathrm{pp}$. The effect size in 
the population of both girls and boys in the area of the left forefoot was moderate. The other parameters, on the other hand, showed a small effect size (Table 2).

Table 2. Distribution of the results of the stabilographic tests at rest and after loading with a backpack in the study group and the statistical significance of differences measured with the Wilcoxon Matched Pairs Test.

\begin{tabular}{|c|c|c|c|c|c|c|}
\hline \multirow{2}{*}{ Parameter } & \multicolumn{2}{|c|}{ Cop-Bars $\left(\mathrm{mm}^{2}\right)$} & \multicolumn{2}{|c|}{ 1-Bars $\left(\mathrm{mm}^{2}\right)$} & \multicolumn{2}{|c|}{ r-Bars $\left(\mathrm{mm}^{2}\right)$} \\
\hline & $S$ & $\mathrm{O}$ & $\mathrm{S}$ & $\mathrm{O}$ & $S$ & $\mathrm{O}$ \\
\hline \multicolumn{7}{|c|}{ boys and girls $(n=100)$} \\
\hline$\underline{x}$ & 198.74 & 187.30 & 57.10 & 55.16 & 76.65 & 74.49 \\
\hline SD & 179.01 & 163.48 & 108.78 & 77.99 & 134.06 & 101.04 \\
\hline $\mathrm{Me}$ & 142.29 & 135.23 & 26.54 & 31.38 & 30.08 & 41.294 \\
\hline $\mathrm{Q}_{1}$ & 76,84 & 84.10 & 15.15 & 14.65 & 15.34 & 19.31 \\
\hline $\mathrm{Q}_{3}$ & 230.78 & 227.34 & 64.60 & 60.96 & 82.06 & 93.43 \\
\hline $\mathrm{p}$ & \multicolumn{2}{|c|}{0.907} & \multicolumn{2}{|c|}{0.364} & \multicolumn{2}{|c|}{0.618} \\
\hline $\mathrm{d}$ & \multicolumn{2}{|c|}{0.12} & \multicolumn{2}{|c|}{0.01} & \multicolumn{2}{|c|}{0.02} \\
\hline \multicolumn{7}{|c|}{ girls $(n=54)$} \\
\hline$\underline{x}$ & 170.46 & 204.23 & 53.34 & 56.29 & 74.41 & 76.54 \\
\hline SD & 147.14 & 183.31 & 119.26 & 68.99 & 134.98 & 116.70 \\
\hline $\mathrm{Me}$ & 115.50 & 150.55 & 23.42 & 34.48 & 26.94 & 31.88 \\
\hline $\mathrm{Q}_{1}$ & 74.94 & 93.47 & 14.19 & 16.61 & 14.69 & 19.57 \\
\hline $\mathrm{Q}_{3}$ & 196.91 & 228.03 & 46.52 & 73.48 & 76.96 & 90.48 \\
\hline $\mathrm{p}$ & \multicolumn{2}{|c|}{0.204} & \multicolumn{2}{|c|}{0.020 * } & \multicolumn{2}{|c|}{0.341} \\
\hline $\mathrm{d}$ & \multicolumn{2}{|c|}{0.36} & \multicolumn{2}{|c|}{0.02} & \multicolumn{2}{|c|}{0.02} \\
\hline \multicolumn{7}{|c|}{ boys $(n=46)$} \\
\hline$\underline{x}$ & 231.93 & 167.42 & 61.52 & 53.82 & 79.28 & 72.09 \\
\hline $\mathrm{SD}$ & 207.16 & 135.91 & 96.16 & 88.16 & 134.42 & 80.06 \\
\hline $\mathrm{Me}$ & 154.44 & 124.84 & 36.75 & 25.80 & 40.23 & 44.93 \\
\hline $\mathrm{Q}_{1}$ & 81.75 & 75.65 & 17.90 & 13.41 & 18.30 & 18.90 \\
\hline $\mathrm{Q}_{3}$ & 308.78 & 210.78 & 68.05 & 47.48 & 86.14 & 102.30 \\
\hline $\mathrm{p}$ & \multicolumn{2}{|c|}{0.097} & \multicolumn{2}{|c|}{0.222} & \multicolumn{2}{|c|}{0.880} \\
\hline $\mathrm{d}$ & \multicolumn{2}{|c|}{0.40} & \multicolumn{2}{|c|}{0.07} & \multicolumn{2}{|c|}{0.06} \\
\hline
\end{tabular}

X-average, SD-standard deviation, Me-median, $\mathrm{Q}_{1}, \mathrm{Q}_{3}-$ quartiles 1 and 3, S-resting measurement, $\mathrm{O}$-measurement with a backpack, $\mathrm{p}$ - significance level of Wilcoxon Matched Pairs Test, cop-bars—the total surface area of the body's center of gravity, l-bars-the surface area of the left foot, r-bars-the surface area of the right foot, ${ }^{*}$ - statistical significance, $d$ - effect size.

\section{Discussion}

During their education in Poland, the majority of students use paper textbooks. Each student has one set of books, and it is impossible to leave textbooks at school due to homework and the need to study for tests. Additionally, in many schools, there are no lockers for pupils where they could leave books that are not needed for the next day or studying at home. The weight of the backpack is additionally increased by personal items carried by students not related to classes.

The longitudinal arch of the foot in humans was formed in phylogenetic development, along with the verticalization of the body posture. The longitudinal arch in vertebrates is only observed in humans. Furthermore, its structure is subject to factors influencing 
the course of ontogenetic development. Significant changes in the size of the foot arch are attributable to the individual's body weight [15-17].

During this cross-sectional study, the authors investigated the relationship between the use of a backpack and changes in the distribution of forces on the plantar side of the foot and body balance in a group of children aged 11 to 14 years. Analysis of the results showed that wearing a backpack affects the arches of the foot and body balance. The main changes in the parameters tested after the application of external load were observed in the entire study population. These changes included the magnitude of pressure forces on the metatarsus and heel of the left foot and the metatarsus of the right foot. The same parameters were statistically significant in the population of girls, but only for the metatarsus and heel area of the left foot in boys. The stabiliographic study only showed statistically significant differences in the population of the girls for the body surface area in the right leg.

The problems of the effect of external load on the distribution of forces on the plantar side of the foot and the level of body balance are increasingly common in scientific considerations. In their study conducted on college students, Jaszczur-Nowicki et al. examined physical exercise during the Harvard test used as a load. The comparative assessment unquestionably showed negative changes in the arch of the feet and the stability of the lower body posture in the women and men studied caused by the physical exercise used [18].

A different approach to the problem was used by Zawadka et al. in a pilot study that investigated the effect of a light, asymmetrical, hand-held load on posture and pressure distribution on the plantar side of the foot in adults with a mean age of 21.5 years [19]. School children very often wear a backpack the wrong way, which, in addition to the issue discussed in the above work, may result in an asymmetric load on the whole body, especially in adolescence. Incorrect loading with a backpack may also result in postural defects in the spine, lower limbs, and individual feet, which is closely related to the distribution of forces on the plantar side of the foot. Incorrect loading increases the effect caused by the backpack's weight itself.

In addition to overloading the body of a young person with a backpack, Bieniek andienieg Wilczyński pointed to the relationships between the parameters of body posture and its stability. They also drew attention to the need for exercises to correct body posture [20]. Interpretation of the above research via comparison with our results shows that the mere wearing of a properly fitted backpack with a certain weight causes changes in posture and the distribution of forces on the plantar side of the foot and balance.

Studies have also analyzed the effects of backpacks on the ground reaction forces acting on children when walking, running, and jumping. An example confirming the results obtained in this study is the research conducted by Barbosa et al. in groups of children aged 10 to 11 and 14 to 15 years. The results showed that the load caused by the backpack influences the ground reaction forces during walking and running [4]. Similar results were obtained by Ahmad and Barbosa after conducting a study on 48 primary school students performing four trials (carrying backpacks weighing $0 \%, 10 \%$, and 15\% of their body weight) over a distance of $10 \mathrm{~m}$. The children walked slower and with a lower number of steps per minute than in the other three conditions. There was no significant effect on stride length. Wearing a backpack with different loads had a significant impact on the distribution of forces on the sole of the foot. It was found that the load mainly had an effect on the contact surface under the metatarsus and heel [21]. The authors of this study made the same observations. In addition, the analysis of the results of this study showed that the flattening of the longitudinal arch of the foot under the load is observed. Similar results were obtained by Alfageme-García et al. in their research on the impact of carrying a backpack on the shape of the feet in children with normal longitudinal arches. During the three-year follow-up, 50 examined children developed supination $(n=18)$ or pronation $(n=32)$ of the foot. A significant relationship was found between wearing a backpack and the risk of developing pronation. Wearing a backpack every day did not change the physiological shape of the foot arch towards supination [22]. 
The problem similar to that discussed in our study was also addressed by Szyszka et al. The aim of their study was to assess the variability of selected stabilographic parameters caused by increasing external load of a school backpack in children aged 10 years. The same backpack was used for the measurements, with its design allowing for a symmetrical distribution of the weight. The school backpack in the subsequent tests accounted for $0 \%, 5 \%, 10 \%$, and $15 \%$ of the body weight of the examined person. The mean variability of the static analysis indices in the studied group of students ranged from $16.5 \%$ for the COP path length to $55.6 \%$ for the difference in the load distribution between the right and left feet. The mean variability of the parameters of dynamic gait analysis ranged from $4.7 \%$ for the left limb stride length to $39 \%$ for lateral symmetry. The authors found differences in load distribution in the standing position for the heel and forefoot areas, both in static and dynamic conditions. Increasing the load led to the differentiation of the arch parameters of the right and left feet with increasing pressure on the area of the forefoot and heel [23]. Similar results were obtained by Pau et al., who analyzed the effect of backpack load on the magnitude of ground reaction force in children aged 6 to 13 years. The analysis also showed that after applying a backpack weight of $5.2 \mathrm{~kg}$, the load on the forefoot area increased [24]. The examinations discussed in the present study showed that after loading with a backpack weighing $5 \mathrm{~kg}$, the impact on the forefoot and toes area decreased. Another example of research dealing with the backpack effect is the study by Hell et al., who analyzed the effect of a $4 \mathrm{~kg}$ backpack load on the gait pattern and postural sway. They examined a group of 12 children aged 7-10 years without any neurological or orthopedic problems. The load of the backpack, averaging 15\% of the body weight, led to a decreased walking speed, shortened walking speed, shortened stride length, and an extended double-support phase. School backpacks weighing $4 \mathrm{~kg}$ caused changes in children's gait, muscle activity, posture, and stability. Due to the weight of the backpack, the center of mass shifted back, and the children's posture became less stable [9]. Similar results were also obtained by Mosaad and Abdelaziem. These scholars found that carrying a backpack weighing $15 \%$ of the child's body weight changes the position of the head and increases the normalized value of the anterior-posterior shear force. Increasing this force may lead to the development of postural disorders and defects [25]. In addition to heavy books and notebooks, students carry different personal items in their backpacks that increase the backpack's weight. Excess weight in the form of a schoolbag during this period of life changes the body posture of school-age children. A partial solution to the problem of too heavy a backpack may be the introduction of digital textbooks by schools.

In their 3-year research, Martínez-Nova et al. showed that the arch of the feet in children shifts towards the physiological norm with age, and the relationship with body weight and height and the weight-height index (BMI) is minimal [26]. Similar results were obtained by Bukowska et al., who analyzed the differences in the arch of the foot and body balance in three age groups of boys training football. It was observed that the total length of the longitudinal arch of both feet in the boys studied tended to flatten in direct proportion to their age. There was also a statistically significant increase in body balance with age [27]. The above results are consistent with the results contained in this paper and another work by Jaszczur-Nowicki, in which the same research methodology was used in a group of children aged 8 to 10 years [28]. Comparison of both papers shows that there are fewer statistically significant differences observed with age, both in the parameters related to the load on the plantar side of the foot and body balance. Based on the previously mentioned studies by Martínez-Nova et al. and Bukowska et al., it can be assumed that the strength of the lower limb muscle groups increases with age, thus increasing body stability. Furthermore, in older school-age children, the external load did not have such a significant impact on the sub-league and stabiliographic parameters. Some of the studies cited in the discussion were carried out on a small group of respondents, and therefore, the results are inconclusive. However, the results obtained in the studies conducted on larger populations coincided with the results and conclusions of the authors of the present study. 


\section{Limitations of the Study}

The main limitation of the study was its cross-sectional nature. The risk factor (carrying a backpack) was assessed in a strictly defined group. Our research did not examine causeand-effect relationships but clearly indicated the need to continue the diagnosis on a larger population. Only children with physiologically normal growth and weight indices participated in the study. In addition, the distribution of forces on the plantar side of the foot during walking was not verified, which could reflect the nature of the study in more detail. In the future, the authors plan to extend the research presented in this paper by taking into account the types of feet of the participants or the physical activity in both static and dynamic tests.

\section{Conclusions}

1. Podological examinations before and after carrying the backpack showed a change in the distribution of forces in the study group. A significant change occurred on the left side, which may indicate a difference in a functionally dominant limb that affects the body balance in children.

2. In the study population, a significant reduction in the longitudinal arch of the foot was found after wearing a backpack.

3. Wearing a backpack caused flattening of the metatarsal area in the study group.

\section{Practical Implication}

The above conclusions may suggest a negative impact of the daily use of a heavy backpack in the study group of school children. Therefore, it can be suggested that the proportion of traditional teaching resources should be changed to increase the use of information technology. However, the final determination of the usefulness of such changes requires further experimental research. Based on the results of our research, attention should be drawn to the need for symmetrical loading of both lower limbs by appropriately putting the backpack on both shoulders in order to properly distribute its weight and avoid scoliosis in children.

Author Contributions: Conceptualization, J.M.B., J.J.-N. and D.K.; methodology, J.M.B., J.J.-N., M.J., T.A., Ł.R. and M.S.; software, J.M.B., J.J.-N.; validation, J.M.B., J.J.-N., D.K., T.A., Ł.R. and M.S.; formal analysis, J.M.B., J.J.-N., T.A., Ł.R. and M.S.; investigation, J.M.B. and J.J.-N.; resources, J.M.B., J.J.-N., M.J., D.K., ŁR. and T.A.; data curation, J.M.B. and J.J.-N.; writing-original draft preparation, J.M.B., J.J.-N., M.J., T.A., Ł.R. and M.S.; writing-review and editing, J.M.B., J.J.-N., M.J., Ł.R. and T.A.; visualization, J.M.B. and J.J.-N.; supervision, J.M.B., J.J.-N., T.A., M.S. and Ł.R.; project administration, J.M.B., J.J.-N., M.J., T.A. and Ł.R.; funding acquisition, J.M.B. and J.J.-N. All authors have read and agreed to the published version of the manuscript.

Funding: This research received no external funding.

Institutional Review Board Statement: The research was conducted on the basis of the consent of the Scientific Research Ethics Committee of the University of Warmia and Mazury in Olsztyn (decision no. 9/2018).

Informed Consent Statement: Informed consent was obtained from all subjects involved in the study.

Data Availability Statement: The data presented in this study are available on request from the corresponding author.

Conflicts of Interest: The authors declare no conflict of interest.

\section{References}

1. Wojtków, M.; Szkoda-Poliszuk, K.; Szotek, S. Influence of body posture on foot load distribution in young school-age children. Acta Bioeng. Biomech. 2018, 20, 101-107. [CrossRef]

2. Li, R.; Liu, Q.; Chen, X.; Yan, S.; Zhao, Y.; Zhang, L.; Badurova, J.; Yang, L.; Fan, H. Load Transference with the Gain of Excessive Body Mass: A Two-Year Longitudinal Study. Int. J. Environ. Res. Public Health 2021, 18, 2879. [CrossRef] [PubMed] 
3. Mesquita, P.R.; Neri, S.; Lima, R.; Carpes, F.P.; de David, A.C. Childhood obesity is associated with altered plantar pressure distribution during running. Gait Posture 2018, 62, 202-205. [CrossRef]

4. Barbosa, J.P.; Marques, M.C.; Neiva, H.P.; Esteves, D.; Alonso-Martínez, A.M.; Izquierdo, M.; Ramirez-Campillo, R.; Alvarez, C.; Marinho, D.A. Effects of Backpacks on Ground Reaction Forces in Children of Different Ages When Walking, Running, and Jumping. Int. J. Environ. Res. Public Health 2019, 16, 5154. [CrossRef] [PubMed]

5. Janakiraman, B.; Ravichandran, H.; Demeke, S.; Fasika, S. Reported influences of backpack loads on postural deviation among school children: A systematic review. J. Educ. Health Promot. 2017, 6, 41. [CrossRef]

6. Hu, H.; Li, S.; Ni, S. Study on Backpack Carrying Health of Children. Adv. Intell. Syst. Comput. 2020, 1203, 378-385. [CrossRef]

7. Alami, A.; Monfared, E.L.; Teimori-Boghsani, G.; Dehaghi, B.F.; Jafari, A.A. Study of Features of Carrying Methods of Backpack by Schoolchildren: A Population-Based Study. Int. J. Pediatr. 2018, 6, 8517-8525. [CrossRef]

8. Rontogiannis, D.; Tsaklis, P.; Mavromoustakos, S.; Kottaras, S. Comparison between two different types of school bags and musculoskeletal symptoms in primary school students. IETI Trans. Ergon. Saf. 2017, 1, 11-21. [CrossRef]

9. Hell, A.K.; Braunschweig, L.; Grages, B.; Brunner, R.; Romkes, J. Einfluss des Schulrucksackgewichtes bei Grundschulkindern: Gang, Muskelaktivität, Haltung und Stabilität. Orthopade 2021, 50, 446-454. [CrossRef]

10. Liu, Y.; Qiang, L.; Song, Q.; Zhao, M.; Guan, X. Effects of Backpack Loads on Leg Muscle Activation during Slope Walking. Appl. Sci. 2020, 10, 4890. [CrossRef]

11. Rashid, M.; Mathew, J.; Vilay, S.R.; Raja, K. Optimization of backpack loads using gait parameters in school boys. J. Bodyw. Mov. Ther. 2021, 25, 174-182. [CrossRef]

12. Puszczałowska-Lizis, E.; Nowak, K.; Omorczyk, J.; Ambroży, T.; Bujas, P.; Nosiadek, L. Foot Structure in Boys with Down Syndrome. BioMed Res. Int. 2017, 2017, 7047468. [CrossRef]

13. Huang, L.; Yang, Z.; Wang, R.; Xie, L. Physiological and biomechanical effects on the human musculoskeletal system while carrying a suspended-load backpack. J. Biomech. 2020, 108, 109894. [CrossRef]

14. Mańko, G.; Kruczkowski, D.; Niźnikowski, T.; Perliński, J.; Chantsoulis, M.; Pokorska, J.; Łukaszewska, B.; Ziółkowski, A.; Graczyk, M.; Starczyńska, M.; et al. The Effect of Programed Physical Activity Measured with Levels of Body Balance Maintenance. Med. Sci. Monit. 2014, 20, 1841-1894. [CrossRef]

15. Drzał, J.; Mrozkowiak, M.; Walicka-Cupryś, K. The influence of obesity on the prevalence of flat foot in children. Young Sport Sci. Ukr. 2007, 4, 110-113.

16. Furgał, W.; Adamczyk, A. Ukształtowanie sklepienia stopy u dzieci w zależności od wskaźnika masy ciała. Med. Sport. 2009, 25, 189-199.

17. Gawron, A.; Janiszewski, M. Płaskostopie u dzieci-Częstość występowania wady a wartości masy i wzrostu odniesione do siatki centylowej. Pol. J. Sport. Med. 2005, 21, 111-122.

18. Jaszczur-Nowicki, J.; Bukowska, J.; Kruczkowski, D.; Spieszny, M.; Pieniążek, M.; Mańko, G. Analysis of students' foot pressure distribution on the ground, as well as their body balance before and after exercise. Phys. Educ. Stud. 2020, 24, 194-204. [CrossRef]

19. Zawadka, M.; Kochman, M.; Jablonski, M.; Gawda, P. Effects of external light load on posture and foot pressure distribution in young adults: A pilot study. Int. J. Ind. Ergon. 2021, 82, 103102. [CrossRef]

20. Bieniek, K.; Wilczyński, J. Analysis of the relationship between body posture and postural stability in girls aged 10-12 years. Med. Stud. 2019, 35, 55-60. [CrossRef]

21. Ahmad, H.N.; Barbosa, T.M. The effects of backpack carriage on gait kinematics and kinetics of schoolchildren. Sci. Rep. 2019, 9, 3364. [CrossRef]

22. Alfageme-García, P.; Calderón-García, J.F.; Martínez-Nova, A.; Hidalgo-Ruiz, S.; Martínez-Álvarez, M.; Rico-Martín, S. Backpacks Effect on Foot Posture in Schoolchildren with a Neutral Foot Posture: A Three-Year Prospective Study. Int. J. Environ. Res. Public Health 2020, 17, 7313. [CrossRef]

23. Paulina, S.; Lichota, M.; Górniak, K. Variability of Postural Stability Parameters Under the Influence of School Backpack Load in Children Aged 10 Years. Adv. Intell. Syst. Comput. 2020, 1223, 131-137. [CrossRef]

24. Pau, M.; Mandaresu, S.; Leban, B.; Nussbaum, M.A. Short-term effects of backpack carriage on plantar pressure and gait in schoolchildren. J. Electromyogr. Kinesiol. 2015, 25, 406-412. [CrossRef] [PubMed]

25. Mosaad, D.M.; Abdel-Aziem, A.A. The relationship between neck angles and ground reaction forces in schoolchildren during backpack carriage. Biomed. Hum. Kinet. 2020, 12, 1-9. [CrossRef]

26. Martínez-Nova, A.; Gijón-Noguerón, G.; Alfageme-García, P.; Montes-Alguacil, J.; Evans, A.M. Foot posture development in children aged 5 to11 years: A three-year prospective study. Gait Posture 2018, 62, 280-284. [CrossRef] [PubMed]

27. Bukowska, J.; Jekiełek, M.; Kruczkowski, D.; Ambroży, T.; Jaszczur-Nowicki, J. Biomechanical Aspects of the Foot Arch, Body Balance and Body Weight Composition of Boys Training Football. Int. J. Environ. Res. Public Health 2021, 18, 5017. [CrossRef]

28. Jaszczur-Nowicki, J.; Bukowska, J.M.; Kruczkowski, D.; Pieniążek, M.; Mańko, G.; Spieszny, M. Distribution of feet pressure on ground and maintaining body balance among 8-10-year-old children with and without external load application. Acta Bioeng. Biomech. 2020, 22, 22. [CrossRef] 